\title{
CRITICAL HEAT FLUX ENHANCEMENT IN POOL BOILING WITH
}

\section{$\mathrm{Al}_{2} \mathrm{O}_{3}$-WATER NANOFLUID}

\author{
Ganesh Annasaheb Matre ${ }^{1}$, R.L.Karwande ${ }^{2}$ \\ ${ }^{1}$ ME student, Mechanical Engineering Department, MSSCET, Jalna, Maharashtra, India \\ ${ }^{2}$ Associate professor, Mechanical Engineering Department, MSSCET, Jalna, Maharashtra, India
}

\begin{abstract}
Boiling is an important phase change phenomena as it plays a crucial role in the design of high heat flux system like boilers, heat exchangers, microscopic heat transfer devices. However boiling phenomenon is limited by critical heat flux. At critical heat flux material of heated surface suffers physical damage due to lower heat transfer resulting from thin film formed over the surface. Now a days Nanofluid which is colloidal suspension of nanoparticle in base fluid is highlighted as innovative techniques to enhance critical heat flux.

In the present study $\mathrm{Al}_{2} \mathrm{O}_{3}$ nanoparticles were characterized by using SEM and XRD analysis. From SEM images it was seen that nanoparticle has spherical morphology, and from XRD analysis average nanoparticle size determined was $29.48 \mathrm{~nm}$. Five different nanofluids of concentration range from 3 gram/liter to 15 gram/liter were prepared. Critical heat flux (CHF) of each $\mathrm{Al}_{2} \mathrm{O}_{3}$-water nanofluid in pool boiling is determined on $\mathrm{NiCr}$ wire of $\mathrm{SWG} \mathrm{28.} \mathrm{The} \mathrm{minimum} \mathrm{critical} \mathrm{heat} \mathrm{flux} \mathrm{enhancement} \mathrm{is}$ $30.53 \%$ at 3 gram/liter nanofluid compared to critical heat flux of distilled water. The highest critical heat flux enhancement is $72.70 \%$ at 12 gram/liter nanofluid. Critical heat flux of nanofluid increases with increase in concentration of $\mathrm{Al}_{2} \mathrm{O}_{3}$ nanoparticle in distilled water up to 12 gram/liter nanofluid. Surface roughness of bare wire was $0.126 \mu$ m. Surface roughness of wire sample used in pool boiling of $3 \mathrm{gram} /$ liter nanofluid is $0.299 \mu \mathrm{m}$ and highest surface roughness was $0.715 \mu \mathrm{m}$ of heater used in pool boiling of 12 gram/liter nanofluid. The Surface roughness measurement results show the evidence of nanoparticle deposition on wire surface and its effect on Critical Heat Flux enhancement.
\end{abstract}

Keywords: Critical heat flux, Nanoparticle, Nanofluid, Concentration, Surface roughness.

\section{INTRODUCTION}

Heat transfer is a very important problem in many industrial applications. Heat transfer in the nucleate boiling regime, the latent heat of vaporization during the change from liquid to gas phase can be exploited, and is the most effective way of cooling thermal systems running at high temperatures. However, the boiling heat transfer is limited by the critical heat flux (CHF). This is the highest heat flux where boiling heat transfer sustains its high cooling performance. When the surface reaches CHF, it becomes coated with a vapor film which isolates the heating surface and the fluid, and the heat transfer decreases dramatically. In these conditions, the wall temperature rises quickly, and if it exceeds the limits of its constituent materials, system failure occurs. For this reason, every system incorporates a safety margin by running at a heat flux lower than $\mathrm{CHF}$, but this approach reduces system efficiency. This compromise between safety and efficiency is a very serious problem in the industry. For this reason, a vast amount of work has been carried out to understand heat transfer mechanisms in nucleate boiling and CHF conditions, and to increase the $\mathrm{CHF}$ point [1].

Several techniques to enhance the CHF have been explored. According to Rohsenow et al. they can be classified into active (requiring external changes to the heater) or passive (requiring no external changes to the heater) methods. Typical active approaches include vibration of the heated surface or the cooling fluid (to increase the bubble departure frequency), heater rotation (to promote bubble departure from and liquid deposition onto the heater surface) and applying an external electric field (to facilitate the bubble departure from the surface by dielectrophoretic force), and passive approaches include coating the surface with porous coatings (to increase the number of active nucleation sites) and oxidation or selective fouling of heater surface (to increase surface hydrophilicity) [2].

A recent passive approach is to create a colloidal suspension of solid nanoparticles in water or other base fluid, called nanofluids. Nanofluids containing several types of nanoparticles have been experimentally found to enhance the critical heat flux (CHF) at very low nanoparticle concentrations. The $\mathrm{CHF}$ is the main constraint in designing cooling systems with high heat capacity because the systems have a tendency to become deformed and broken due to dryout of the heat transfer surface, which causes sudden rise in the heating surface. Therefore, CHF enhancement is directly related to possible improvement in the system safety margin and the performance of cooling systems with high heat capacity, which is particularly applicable in nuclear power plants. Many researchers have investigated the use of nanofluids to enhance the CHF over the last few decades [3]. 


\section{Nomenclature}

A heater surface area

g Gravitational acceleration

I Electric current

V Voltage

$\mathrm{R}_{\mathrm{a}} \quad$ Roughness parameter

L Length

d diameter of nanoparticles

q" Critical Heat Flux

D Diameter of wire

XRD X ray Diffraction

SEM Scanning Electron Microscope

CHF Critical Heat Flux

$\mathrm{h}_{\mathrm{fg}} \quad$ Latent heat of vaporization

Exp Experimental

Avg Average

\section{Greek Symbols}

$\Sigma \quad$ Surface tension

$\rho \quad$ Density

$\lambda \quad$ X ray wavelength

$\beta \quad$ Full width at half of maximum intensity in radians

$2 \theta$ diffraction angle

\section{Subscripts}

$1 \quad$ Liquid

v vapor

CHF Critical heat flux

sat saturation

s Surface

Z Zuber correlation for $\mathrm{CHF}$

\section{EXPERIMENTATION}

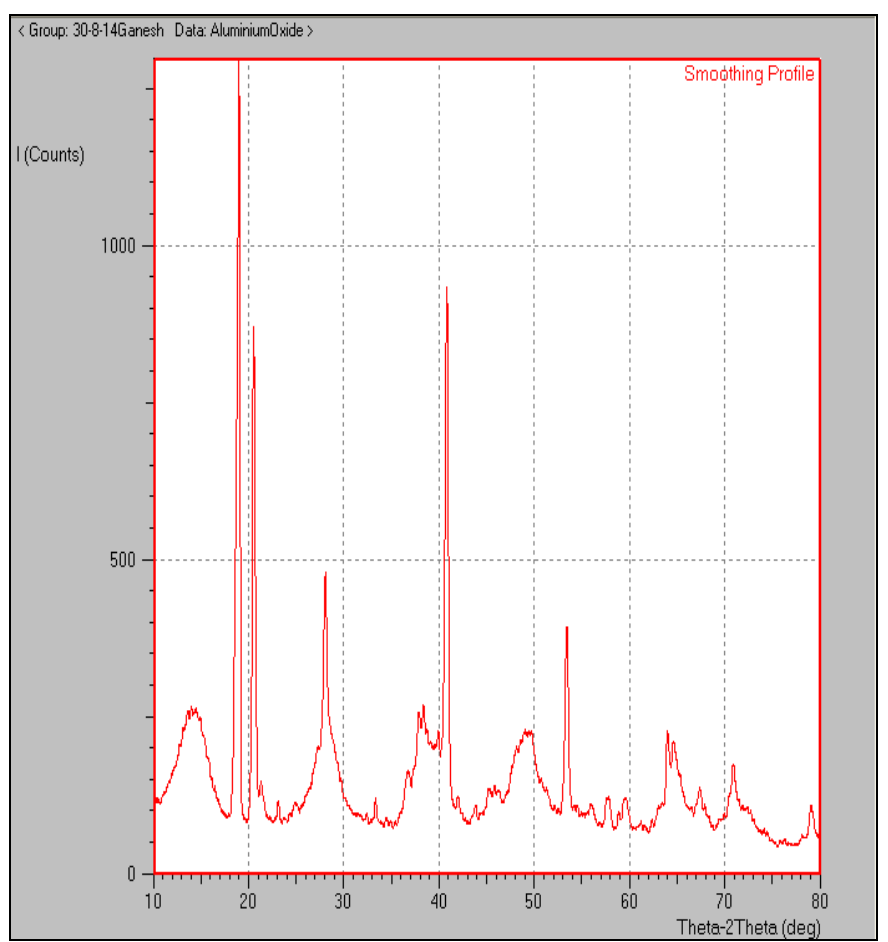

Fig -1: Diffraction pattern for $\mathrm{Al}_{2} \mathrm{O}_{3}$ nanoparticles

\subsection{Nanoparticle Characterization}

$\mathrm{Al}_{2} \mathrm{O}_{3}$ nanoparticles were brought from Nano Labs, Jamshedpur, Jharkhand. As nanoparticle material, size, morphology and concentration affects nanofluid pool boiling characteristics. Therefore it is needed to find out the exact average size of nanoparticles and its morphology.

\subsection{X-Ray Diffraction of $\mathrm{Al}_{2} \mathrm{O}_{3}$ Nanoparticles}

The high-intensity peaks result when the Bragg diffraction condition is satisfied. Figure 1 depicts the X-ray diffraction spectra of $\mathrm{Al}_{2} \mathrm{O}_{3}$ nanoparticles taking intensity on vertical axis and ' $2 \theta$ ' on horizontal axis.

The average size of the nanoparticle was determined by the following Scherrer's formula given as [4].

$$
d=\frac{0.9 \times \lambda}{\beta \times \operatorname{Cos} \theta}
$$

The average size of the nanoparticles measured by using Scherrer's formula was equal to $29.48 \mathrm{~nm}$.

\subsection{SEM Examination of $\mathrm{Al}_{2} \mathrm{O}_{3}$ Nanoparticles}

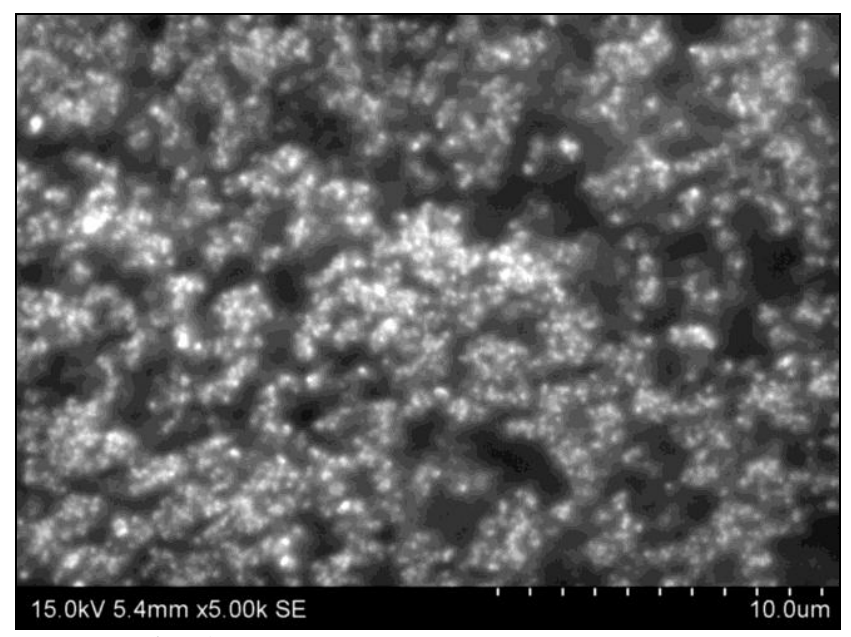

Fig -2: $\mathrm{SEM}$ image of $\mathrm{Al}_{2} \mathrm{O}_{3}$ nanoparticles

The SEM image of $\mathrm{Al}_{2} \mathrm{O}_{3}$ nanoparticles at $10 \mu \mathrm{m}$ magnifications is shown in figure 2 .

SEM micrographs show the spherical morphology of $\mathrm{Al}_{2} \mathrm{O}_{3}$ nanoparticles. Thus, $\mathrm{Al}_{2} \mathrm{O}_{3}$ nanoprticle are having spherical morphology with average nanoparticles size $29.48 \mathrm{~nm}$.

\subsection{Experimental Set Up and Procedure}

The pool boiling experimental setup is shown in figure 3 . The main test pool consists of a Borosilicate glass beaker having size $15 \mathrm{~cm}$ diameter and $21.5 \mathrm{~cm}$ height. Glass was clearly transparent. Thus the boiling phenomenon can be observed. Two Bakelite sheet of thickness $15 \mathrm{~mm}$ used. Top Bakelite cover was used to cover the top side of the glass container so that the vapor will not leave the container. It has a hole at the centre to fix the condenser which was used 
to condense the vapor escaping from container to maintain constant nanofiuid level inside the container. Central hole of condenser ensure atmospheric condition inside the container. Inner Bakelite disk was inserted inside the container to hold four Copper electrodes. These Bakelite top cover and inner Bakelite disk were bolted each other firmly. Top Bakelite cover was having small holes for thermocouple and wire to supply current to copper electrodes.

A fluid heater of $1 \mathrm{~kW}$ was used to heat the water and nanofluid to the saturation temperature. The CHF of distilled water and $\mathrm{Al}_{2} \mathrm{O}_{3}$ nanofluid was measured with a $\mathrm{NiCr}$ wire of 28 SWG (0.3759 mm diameter) horizontally submerged in the test fluid at atmospheric pressure. Length of test wire was $110 \mathrm{~mm}$. Four copper electrodes were used having diameter $5 \mathrm{~mm}$. Two copper electrodes were used to supply current to fluid heater. Other two Copper electrodes were used to supply measured DC power to test wire. Both ends of the $\mathrm{NiCr}$ wire heater were tightly secured to the clamps of the copper electrodes.

These copper electrodes were bolted to the inner Bakelite disc inside the container firmly. The pool temperature was measured with a thermocouple of K-type. DC rectifier was used to supply DC power to test heater. By knob provided on the rectifier, the DC current and voltage was varied.

All pool boiling experiments were conducted saturated temperature $\left(100^{\circ} \mathrm{C}\right)$. Test fluid was heated to saturation temperature. Once the saturation temperature of test fluid was reached, the fluid heater was switched off and the DC power supply to the $\mathrm{NiCr}$ wire was switched on. The experiments were conducted by increasing the electric power supply to the wire (test wire). Initially DC supply was increased with large step. As the wire was becoming red hot the DC supply was increased in smaller steps using variac. For each incremental step Voltage and current were recorded during test. At particular Voltage and current $\mathrm{NiCr}$ wire breaks, corresponding Voltage and current just before burn out point is recorded and used to calculate CHF of test fluid.

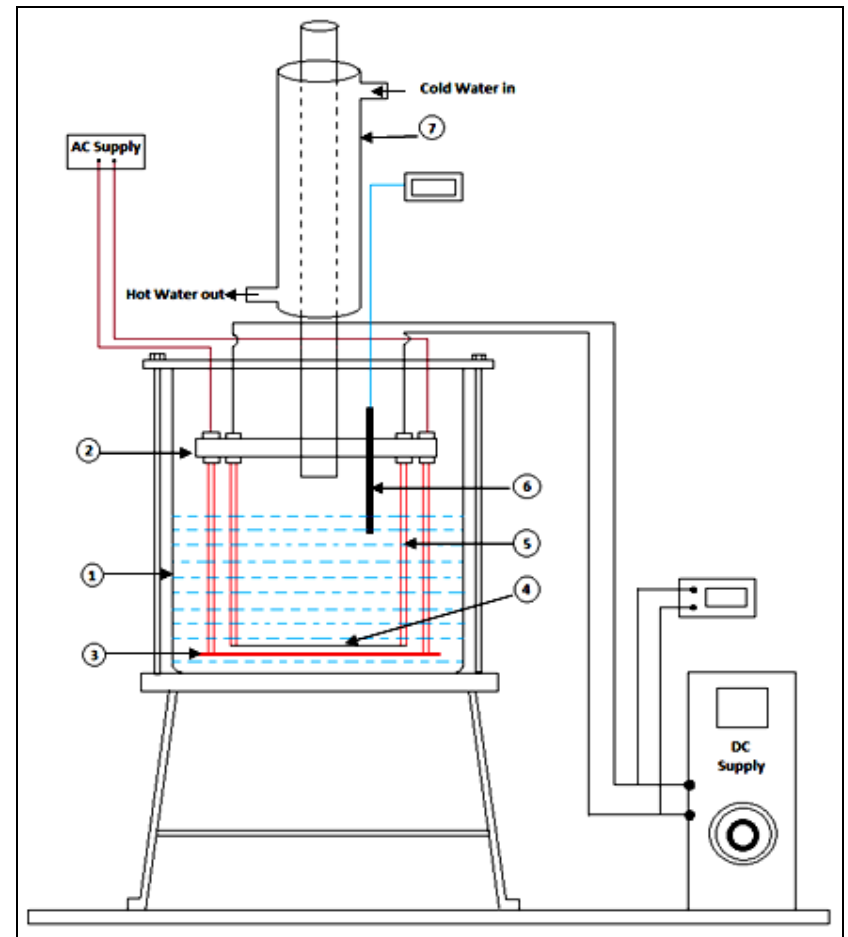

Fig - 3: Schematic of pool boiling experimental setup

Components of experimental setup are as:
1. Glass beaker
5. Copper electrode
2. Bakelite cover
3. Fluid heater
6. Thermocouple
4. Test wire
7. Condenser

Experimental critical heat flux is determined [5] by following formula as:

$$
\mathrm{q}^{\prime \text { Experimental }}=\frac{V_{C H F} \times I_{C H F}}{A}
$$

$A=$ Surface area of heater surface

$\mathrm{A}=\pi \times \mathrm{D} \times \mathrm{L}$

$\mathrm{V}_{\mathrm{CHF}}=$ Voltage at $\mathrm{CHF}$

$\mathrm{I}_{\mathrm{CHF}}=$ Current at $\mathrm{CHF}$

The main sources of uncertainty of the applied voltage and current are due to contact resistance between the wire heater and electrodes [6]. In addition, there is uncertainty associated with the length and diameter of the $\mathrm{NiCr}$ wire heater. The measurement uncertainty is calculated using the method by Holman [7] as given in Equation (3).

$$
\frac{U^{\prime \prime}}{\mathrm{q}^{\prime \prime}}=\sqrt{\left[\left(\frac{U_{I}}{I}\right)^{2}+\left(\frac{U_{V}}{V}\right)^{2}+\left(\frac{U_{D}}{D}\right)^{2}+\left(\frac{U_{L}}{L}\right)^{2}\right]}
$$

The uncertainties in the Voltage, Current, Length and diameter of wire measurement are $3.44 \%, 3.98 \%, 1.81 \%$ and $5.32 \%$ respectively. The maximum estimated uncertainty of the heat flux measurement is $7.69 \%$. 


\subsection{Preparation of Nanofluid}

In this work, nanofluids were prepared by the two-step method, dispersing dry nanoparticles into the base liquid followed by magnetic stirring. Distilled water was used as the base liquid, and $\mathrm{Al}_{2} \mathrm{O}_{3}$ nanoparticles were used without the addition of additives. The $\mathrm{Al}_{2} \mathrm{O}_{3}$ nanoparticles were procured from Nano lab having $99 \%$ purity with an average size of $29.48 \mathrm{~nm}$. Magnetic stirring was performed for 6 hour just before pool boiling experiments.

Concentrations of $\mathrm{Al}_{2} \mathrm{O}_{3}$ water nanofluids were as follows.

1. 4.5 gram of $\mathrm{Al}_{2} \mathrm{O}_{3}$ nanoparticles in 1.5 liter of distilled water.(i.e 3 gram/liter)

2. 9 gram of $\mathrm{Al}_{2} \mathrm{O}_{3}$ nanoparticles in 1.5 liter of distilled water.(i.e 6 gram/liter)

3. 13.5 gram of $\mathrm{Al}_{2} \mathrm{O}_{3}$ nanoparticles in 1.5 liter of distilled water.(i.e 9 gram/liter)

4. 18 gram of $\mathrm{Al}_{2} \mathrm{O}_{3}$ nanoparticles in 1.5 liter of distilled water.(i.e 12 gram/liter)

5. 22.5 gram of $\mathrm{Al}_{2} \mathrm{O}_{3}$ nanoparticles in 1.5 liter of distilled water.(i.e15 gram/liter)

In beaker of $500 \mathrm{ml}$ capacity, $400 \mathrm{ml}$ distilled water was taken. Required mass of $\mathrm{Al}_{2} \mathrm{O}_{3}$ nanoparticles was taken by weighing on a digital electronic balance. Magnetic Needle was kept in the beaker. This beaker was placed on Magnetic stirrer. Magnetic stirrer supply was turned on and the stirring was kept on maximum speed. $\mathrm{Al}_{2} \mathrm{O}_{3}$ nanoparticles were added into the distilled water very slowly. Through this preparation temperature of the fluid was increased slowly. This solution was stirred for 5 hours continuously. Then this solution was poured into beaker of capacity 3 liter having $1100 \mathrm{ml}$ of distilled water and was stirred for 1 hour. This prepared nanofluid was used in pool boiling experiment.

As since the characteristics of nanofluids are governed by not only the kind and size of the nanoparticles but also their dispersion status in the base fluid, it is essential to have the test fluid sample without any agglomeration. To ensure no agglomeration, after magnetic stirrer for 6 hour, the test fluid sample was collected in a glass vessel and left for 1 hour to verify any agglomeration of the particle and subsequent settling in the vessel bottom. It was found that negligible agglomeration in the first 60 minutes. Considering the duration of the test run which is roughly 4 minutes, no agglomeration for the first 60 minutes was more than enough to get reliable results from the experimentation.

$\mathrm{Al}_{2} \mathrm{O}_{3}$ nanopaticles were white in color; hence nanofluids formed were white in color. It is observed as the nanopaticle concentration was increased nanofluid color becomes darker.

\section{RESULT AND DISCUSSION}

\subsection{Validation of Experimental Setup}

To validate the accuracy of the experimental setup, experiments were carried out with distilled water [8]. CHF in pool boiling are compared with the most widely accepted Zuber's correlation [9]. It is given by:

$$
\mathrm{q}^{\prime \prime} \mathrm{z}=0.131 \times h_{f g \times\left[\sigma \times g \times \rho v^{2}(\rho l-\rho v)\right]^{\frac{1}{4}}}
$$

Where, CHF is in $\mathrm{W} / \mathrm{m}^{2}$.

The predicted value of critical heat flux of distilled water at $100^{\circ} \mathrm{C}$ by using Zubers correlation is $1.11 \mathrm{MW} / \mathrm{m}^{2}$.

Critical heat flux is determined for distilled water at saturated temperature by performing ten pool boiling experiments. Average value of $\mathrm{CHF}$ is determined by taking average of $\mathrm{CHF}$ of ten experiments.

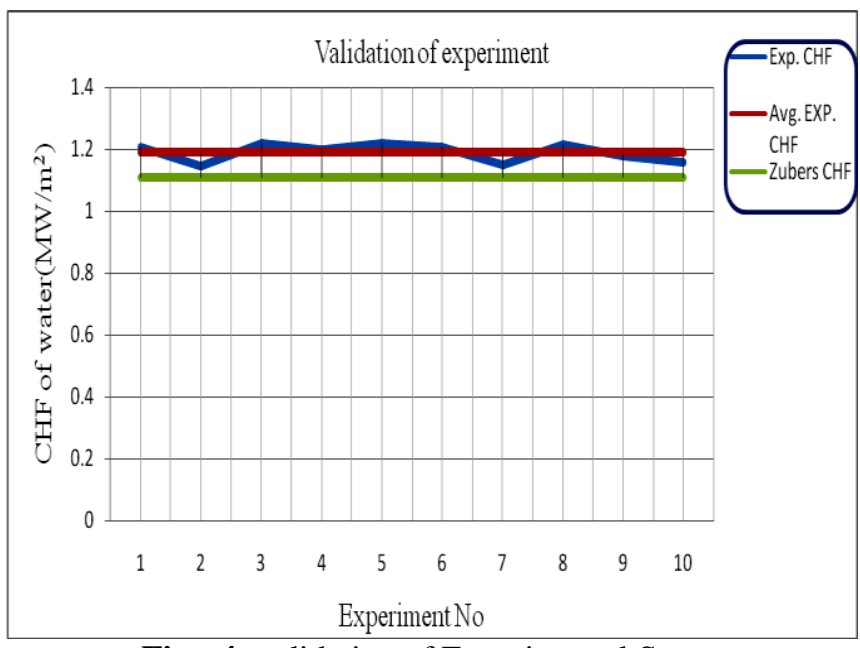

Fig - 4: validation of Experimental Setup

Average critical heat flux for experimental method is 1.189 $\mathrm{MW} / \mathrm{m}^{2}$ which is $7.12 \%$ more than theoretical critical heat flux predicted by Zubers correlation. In all the experiments critical heat flux is deviated from theoretical critical heat flux in acceptable range. Hence experimental test rig is validated.

\subsection{CHF of Nanofluid at Different Concentration}

In the present experimentations, concentration of nanofluid was varied from 3 gram/liter to 15 gram/liter. At each concentration $\mathrm{CHF}$ values were determined by performing five experiments. CHF values for that particular concentration was considered as average of five experiments.

Figure 5 shows measured $\mathrm{CHF}$ values of $\mathrm{Al}_{2} \mathrm{O}_{3}$-water nanofluid at different nanoparticle concentrations.

From pool boiling experiments results it is clear that CHF of nanofluid is greater than that of distilled water. CHF of nanofluids is strongly dependent on nanoparticle concentration. 


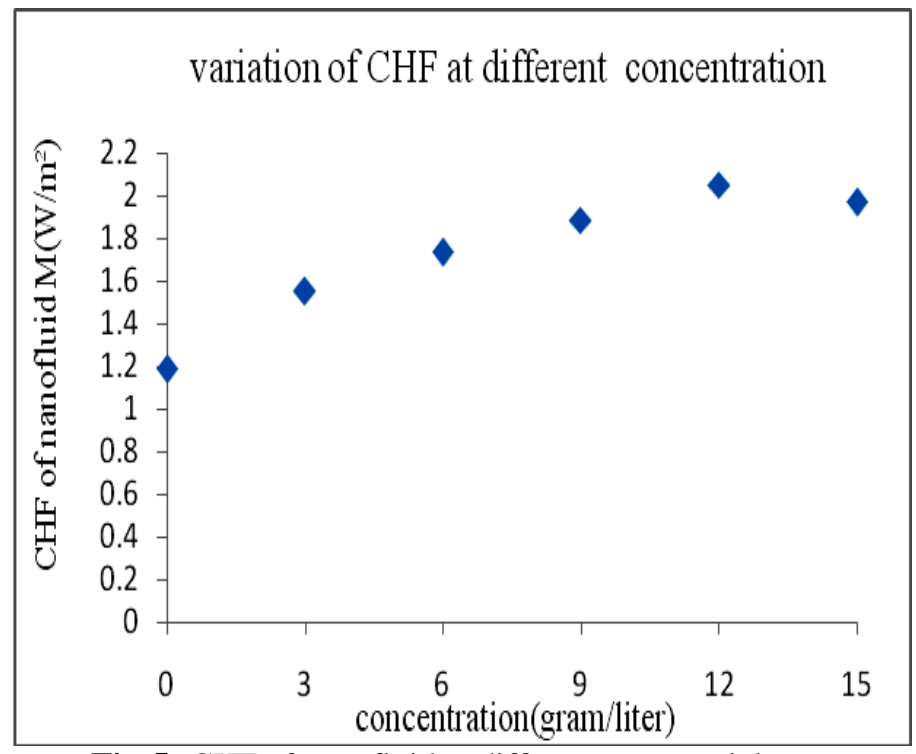

Fig-5: CHF of nanofluid at different nanoparticle concentrations

Figure 6 shows percentage of CHF enhancement at different nanoparticle concentration.

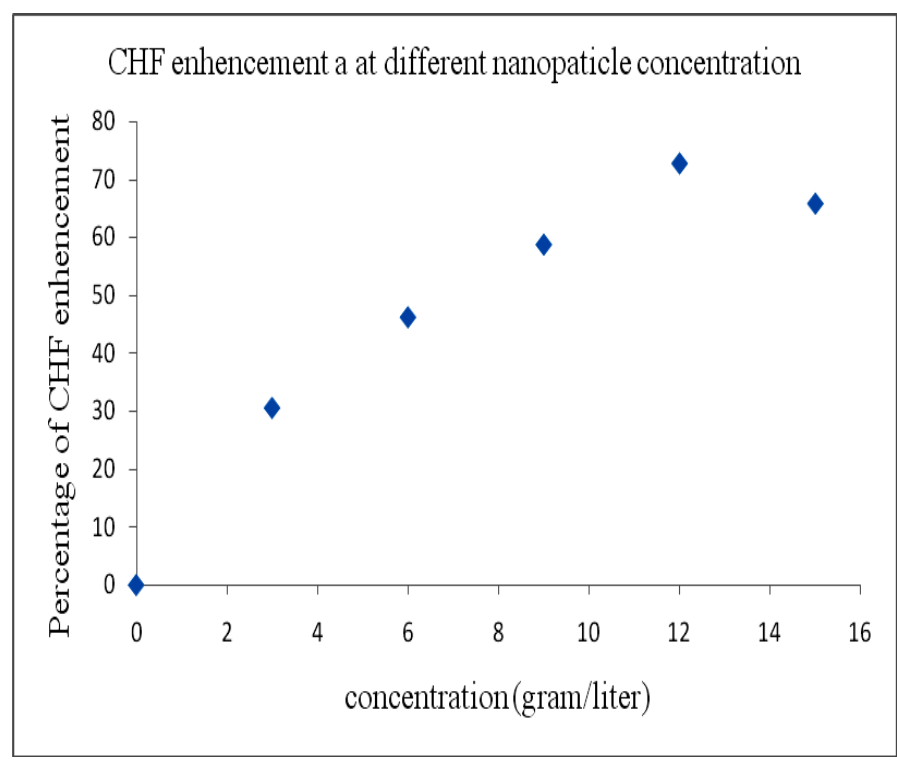

Fig- 6: Percentage of CHF enhancement at different nanoparticle concentration.

In experimentations for $\mathrm{Al}_{2} \mathrm{O}_{3}$-water nanofluid with a lowest concentration i.e. 3 gram/liter, average value of $\mathrm{CHF}$ is $1.552 \mathrm{MW} / \mathrm{m}^{2}$. At this concentration $\mathrm{CHF}$ enhancement is $30.53 \%$. Further as the concentration of nanofluid increased to the 6 gram/liter, average $\mathrm{CHF}$ value measured is 1.738 $\mathrm{MW} / \mathrm{m}^{2}$ having $46.17 \%$ enhancement.

Similarly, increasing trend of $\mathrm{CHF}$ is observed for 9 gram/liter and 12 gram/liter nanofluid.CHF at 9 gram/liter $\mathrm{Al}_{2} \mathrm{O}_{3}$-water nanofluid is $1.887 \mathrm{MW} / \mathrm{m}^{2}$ which indicate $58.70 \% \mathrm{CHF}$ enhancement. For 12 gram/liter nanofluid CHF $2.053 \mathrm{MW} / \mathrm{m}^{2}$ is obtained with $72.70 \%$ enhancement. In case 12 gram/liter nanofluid highest $\mathrm{CHF}$ is obtained.
But for 15 gram/liter $\mathrm{Al}_{2} \mathrm{O}_{3}$-water nanofluid $\mathrm{CHF}$ value is smaller than 12 gram/liter $\mathrm{Al}_{2} \mathrm{O}_{3}$-water nanofluid. For 15 gram/liter nanofluid CHF obtained is $1.971 \mathrm{MW} / \mathrm{m}^{2}$ showing $65.77 \% \quad \mathrm{CHF}$ enhancement compared to experimental CHF of distilled water.

From above discussion it is clear that CHF increases with nanoparticle concentration up to 12 gram/liter nanofluid concentration as compared to experimental CHF of distilled water, showing highest $\mathrm{CHF}$ enhancement at 12 gram/liter nanoparticle concentration.

Thus, nanoparticle clearly plays important role in $\mathrm{CHF}$ enhancement of basefluid.CHF enhancement increases with increase in concentration up to certain concentration beyond which CHF decrease even though there is increased in concentration of nanofluid.

\subsection{Surface Roughness of Heater Surface Used In Pool Boiling of Nanofluid}

The use of nanofluid in pool boiling experimentation has an effect on the heater surface roughness. When the nanofluid evaporates at the boiling surface, it leaves behind nanoparticles that adhere to the boiling surface. This builds up of nanoparticle layer on the boiling surface. Thus, surface roughness changes. Also, a rougher surface increases nucleation site density, the physical locations at which the boiling process begins.

The effect of nanoparticle concentration on surface roughness of wire is needed to find out. Hence surface roughness of wire surface before pool boiling and wire used in pool boiling of nanofluid at different concentration is measured. More specifically surface roughness is defined as the measurement of vertical deviation of a real surface from its ideal surface. The parameter, which is used in this investigation, is the $R_{a}$ value. The $R_{a}$ value is defined as the arithmetic average of the vertical deviation from the mean line established in a surface roughness measurement and has unit usually $\mu \mathrm{m}$.

Wire heater surface roughness before pool boiling experiment is $0.126 \mu \mathrm{m}$. The wire sample which is used in nanofluid pool boiling of 3 gram/liter concentration shows surface roughness $0.299 \mu \mathrm{m}$. Similarly surface roughness increasing trend is observed for nanoparticle concentration from 6 gram/liter to 12 gram/liter. Surface roughness of wire sample used in 6 gram/liter nanofluid pool boiling is 0.507 $\mu \mathrm{m}$. while wire sample used in pool boiling of 9 gram/liter nanofluid shows value of surface roughness $0.678 \mu \mathrm{m}$.

Highest surface roughness of wire sample used in pool boiling of $12 \mathrm{gram} /$ liter nanofluid is $0.715 \mu \mathrm{m}$. Surface roughness of wire sample used in pool boiling of 15 gram/liter nanofluid is $0.385 \mu \mathrm{m}$. This roughness value is more than bare wire but less than 12 gram/liter nanofluid. 


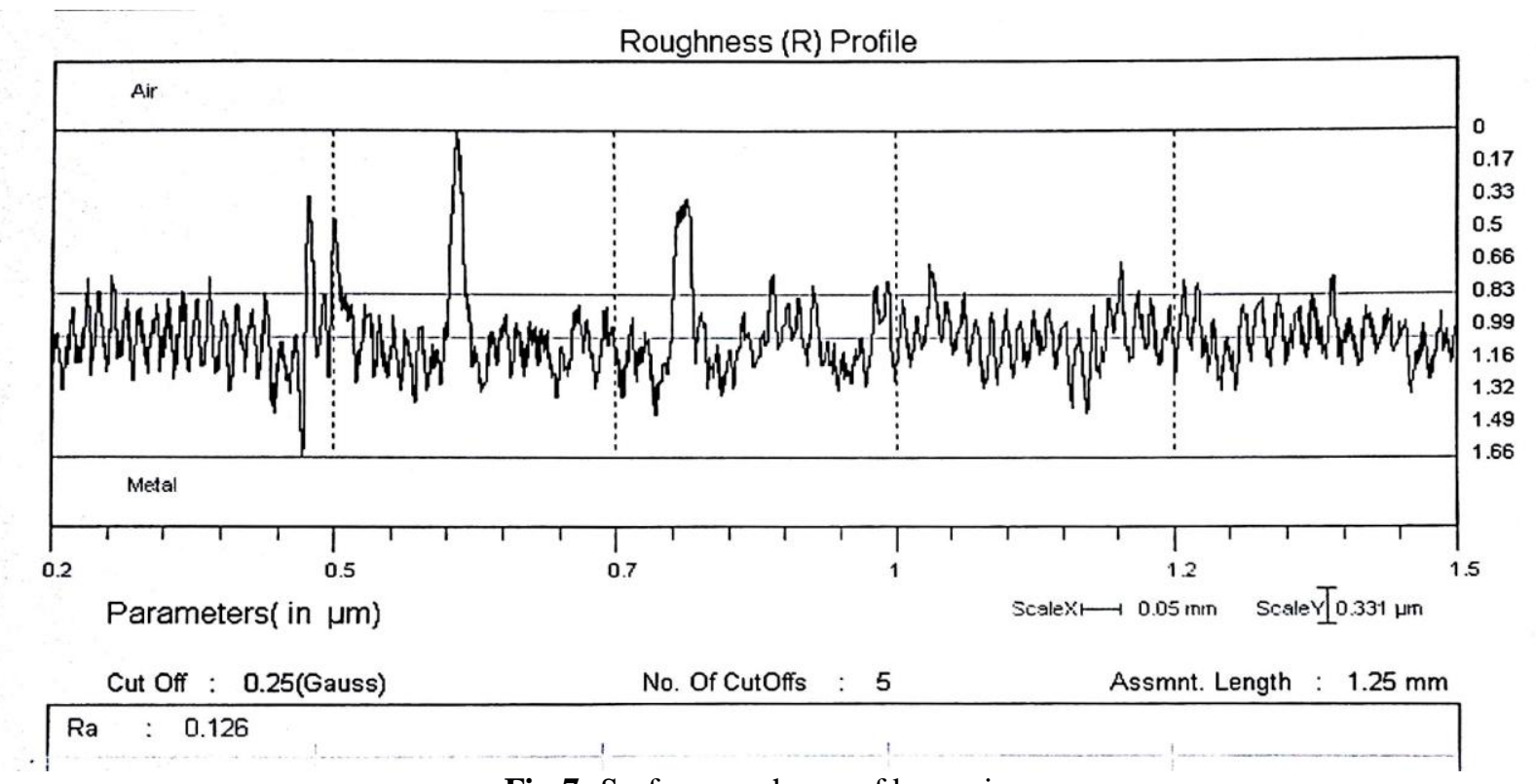

Fig-7: Surface roughness of bare wire

Roughness (R) Profile

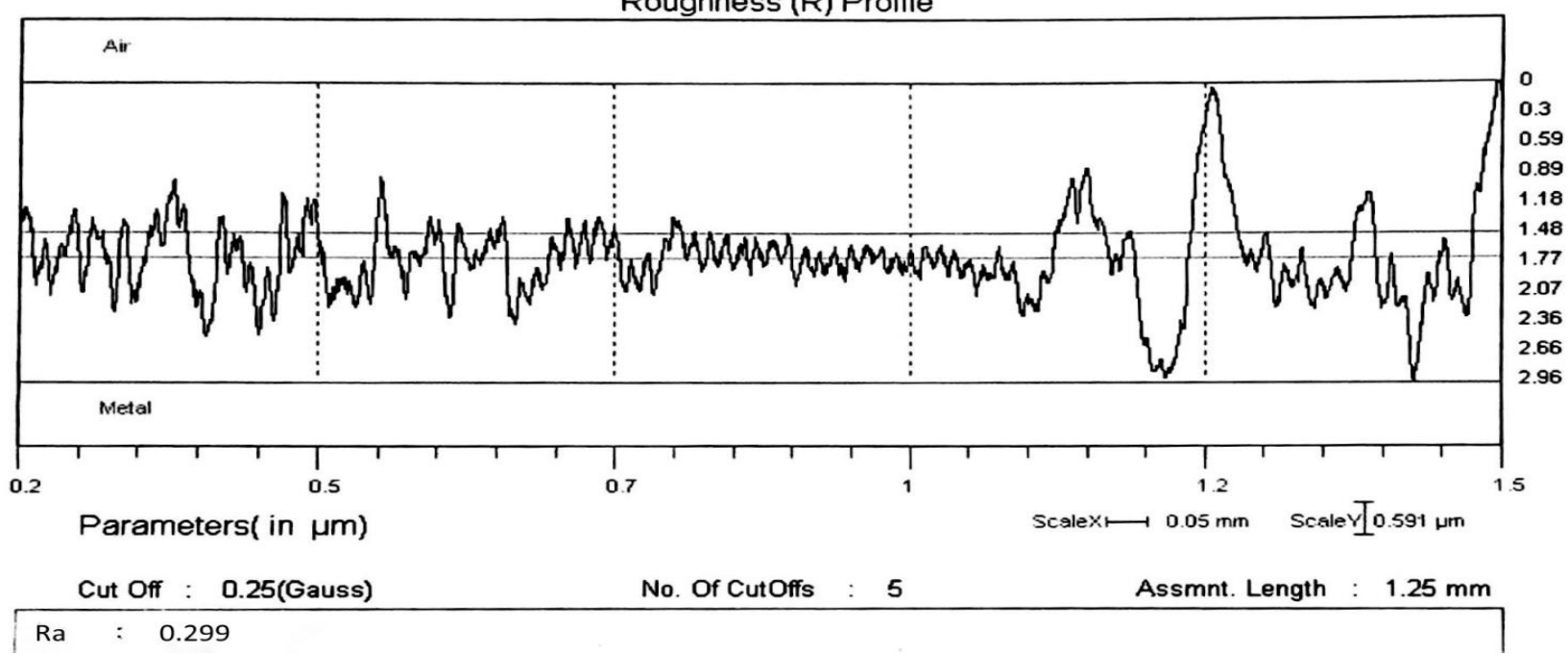

Fig-8: Surface roughness of wire used in 3 gram/liter nanofluid

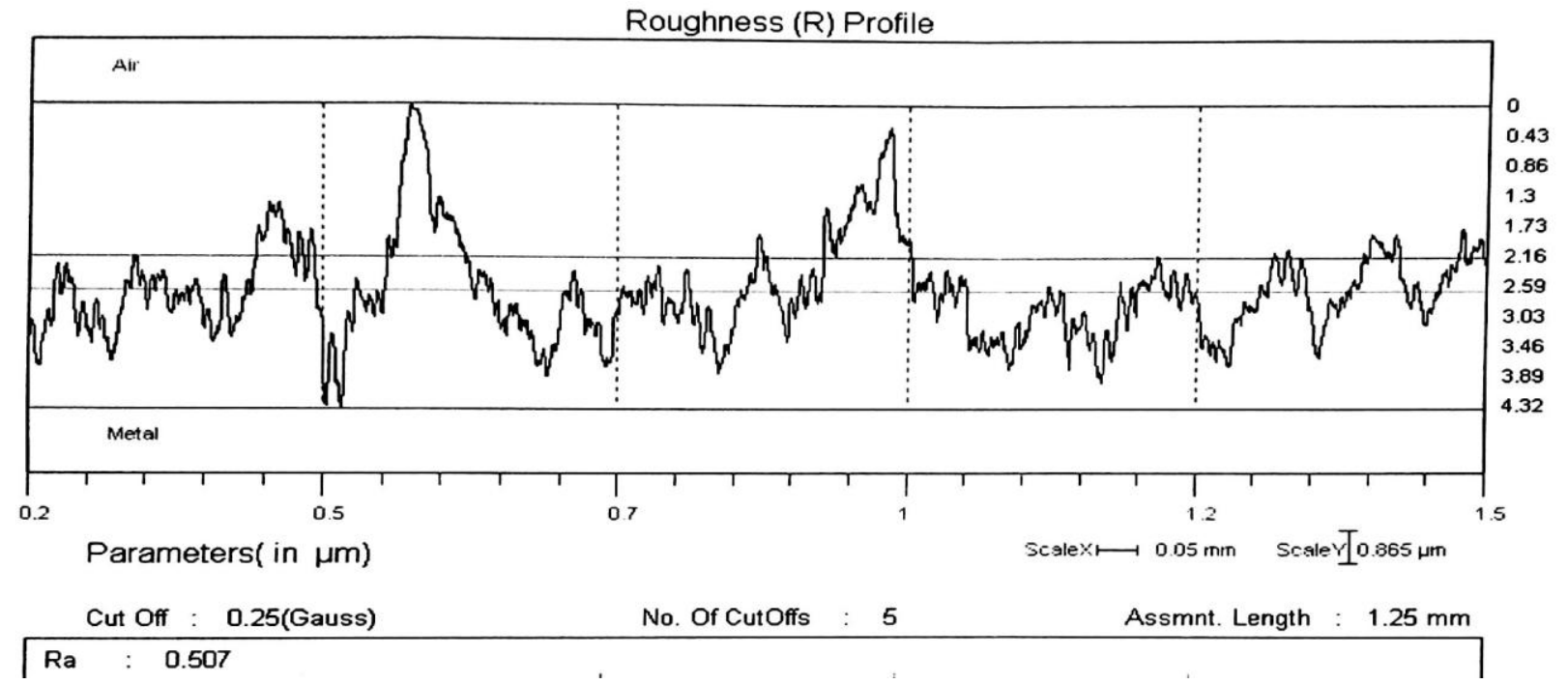

Fig-9: Surface roughness of wire used in 6 gram/liter nanofluid 


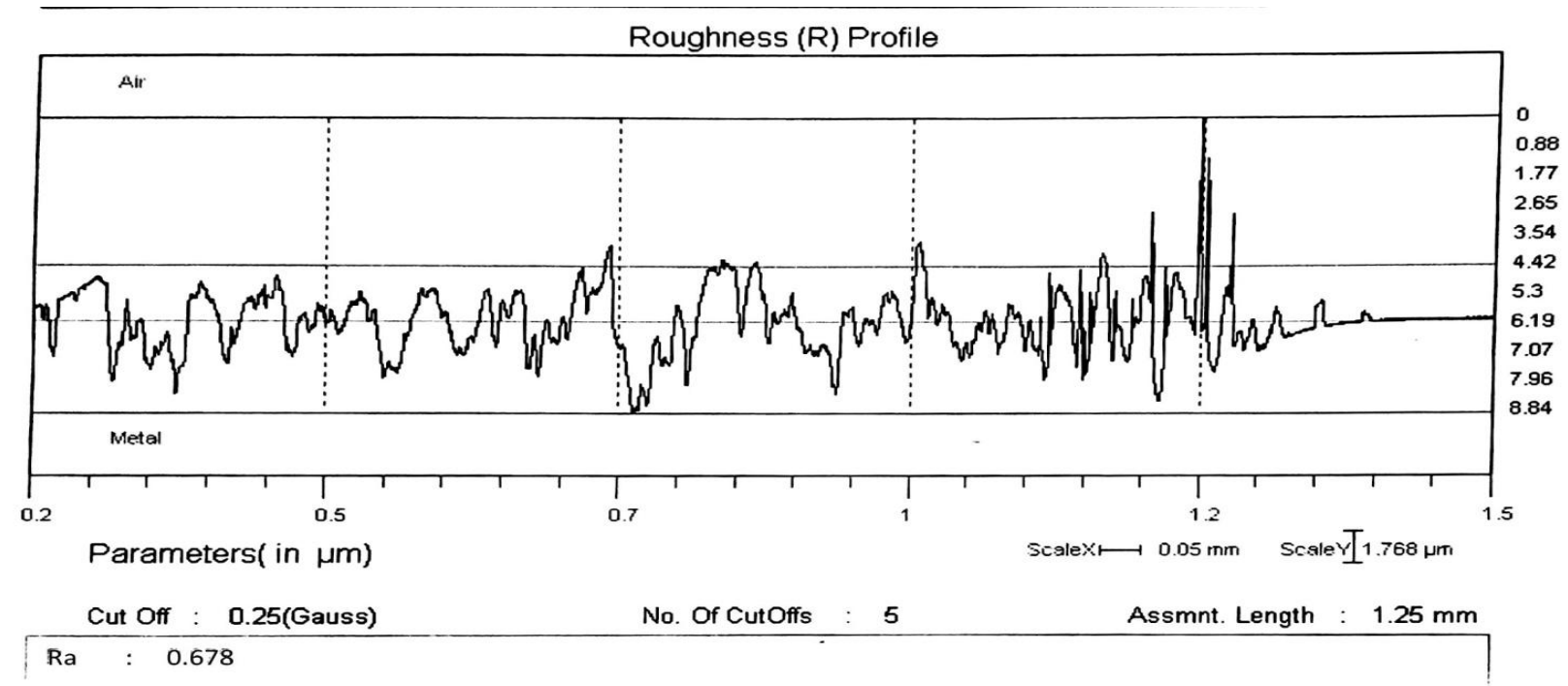

Fig-10: Surface roughness of wire used in 9 gram/liter nanofluid

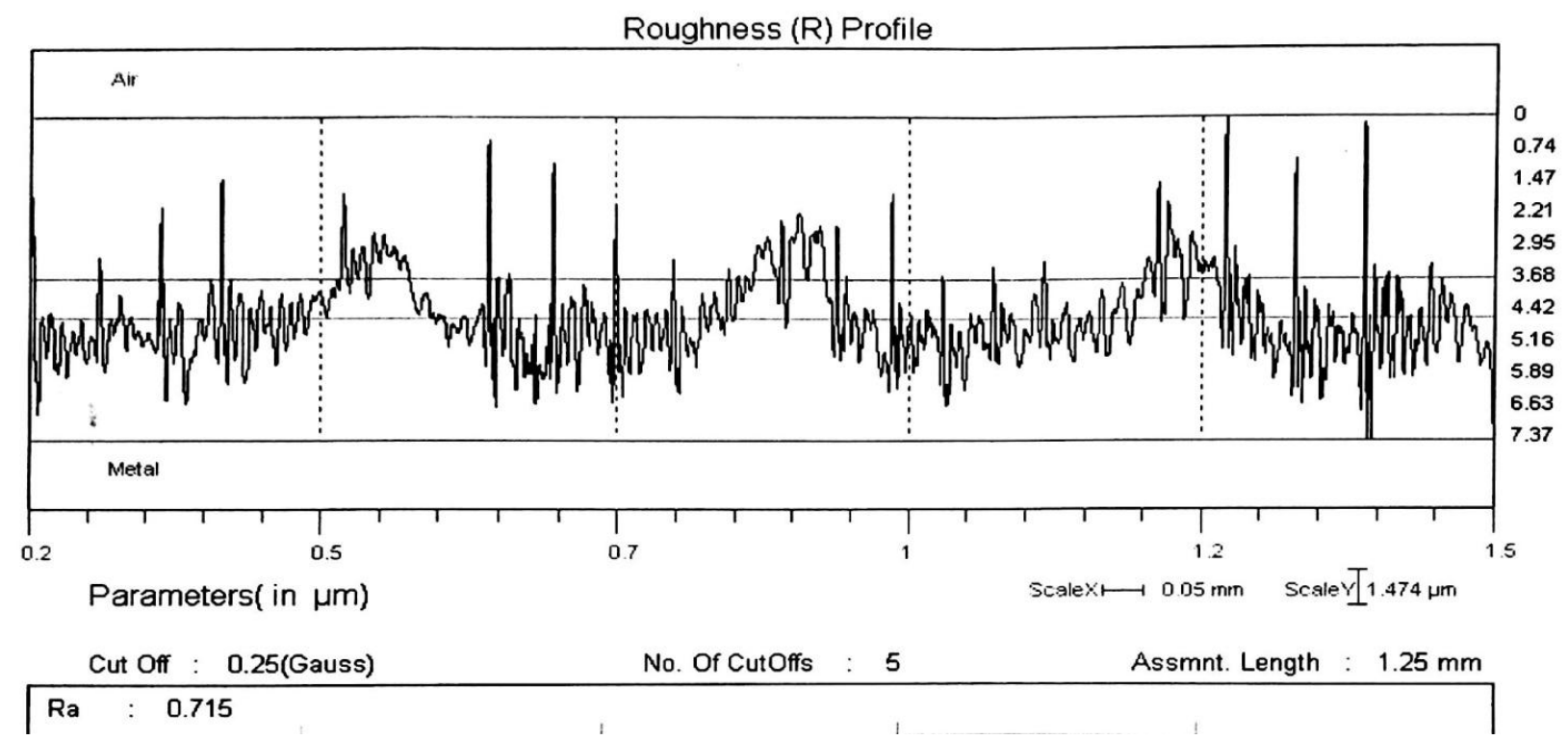

Fig-11: Surface roughness of wire used in 12 gram/liter nanofluid

Roughness (R) Profile

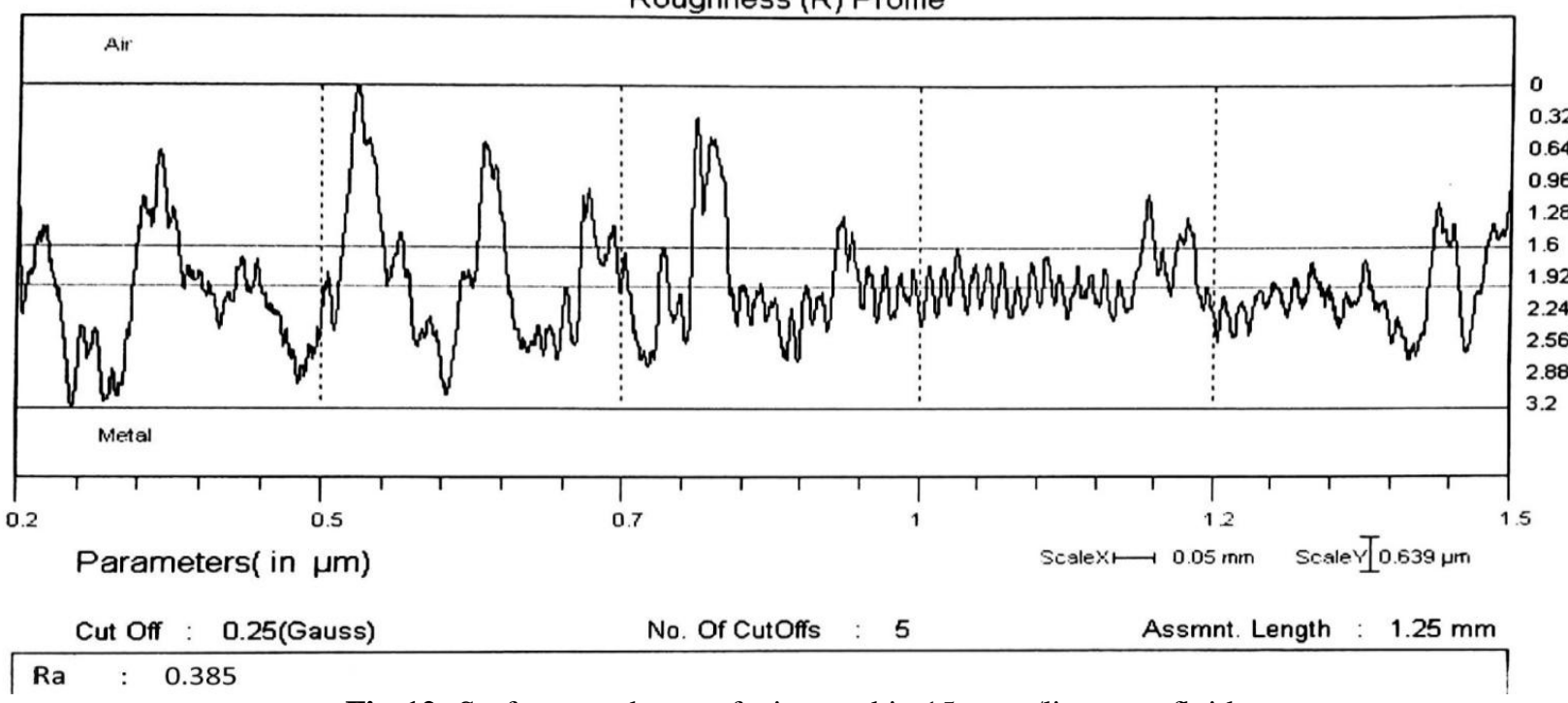

Fig-12: Surface roughness of wire used in 15 gram/liter nanofluid 


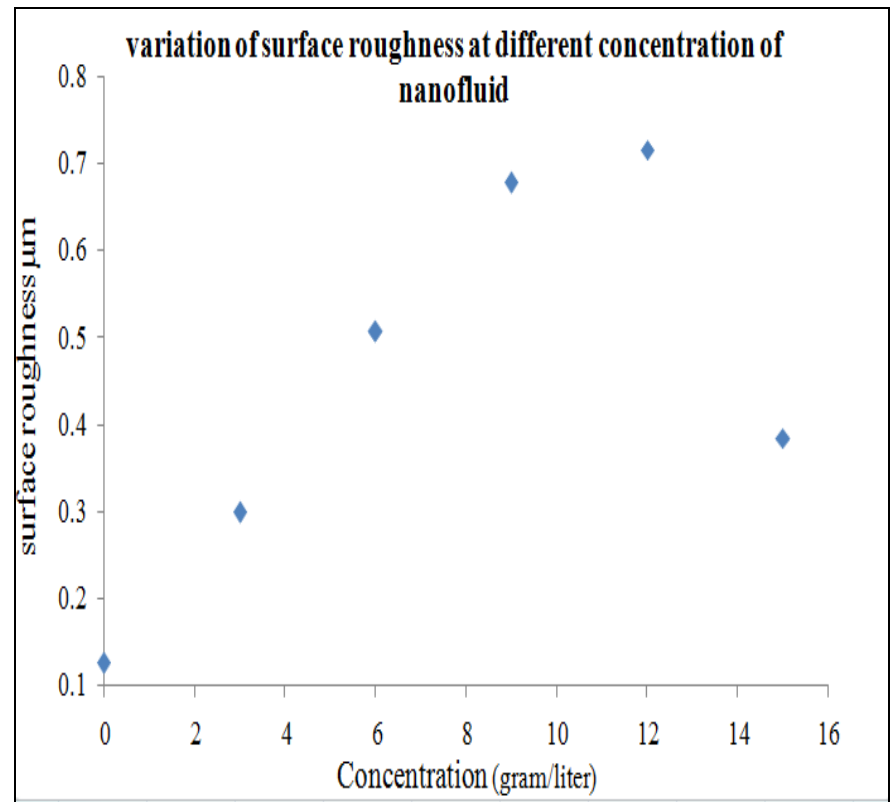

Fig-13: Surface roughness at different concentration

Thus, surface roughness value of bare wire changes when it is used in pool boiling of nanofluid. Also surface roughness value depends upon concentration of nanofluid. Surface roughness value increases with increase in concentration upto 12 gram/liter, beyond which even though there is increase in concentration surface roughness decreases. Thus nanoparticles are responsible for change in surface roughness of wire sample.

While in case of 15 gram/liter nanofluid, nanoparticles are more in number than 12 gram/liter nanofluid. Surface roughness value depends on heater surface porosity and nanoparticle size. In case of 15 gram/liter nanofluid, smooth surface of the wire might be due to nanoparticles deposition on heater surface forming porous layer having micro cavities followed by deposition of extra nanoparticle in those micro cavities. Hence surface roughness of wire sample used in 15 gram/liter nanoparticle concentration decreases compared to 12 gram/liter nanoparticle concentration.

\subsection{Effect of Heater Surface Roughness and}

\section{Nanoparticle Concentration on CHF}

When nanoparticle is added to base fluid CHF enhancement occurs in pool boiling. CHF enhancement increases with nanoparticle concentration from 3 gram/liter to 12 gram/liter nanparticle concentration, then for 15 gram/liter nanoparticle concentration $\mathrm{CHF}$ enhancement decreases.

Likewise, Surface roughness of wire surface increases when it is used in increased nanoparticle concentration up to 12 gram/liter concentration then for 15 gram/liter concentration surface roughness value decreases as compared to 12 gram/liter nanoparticle concentration.

These results clearly indicates that in pool boiling of nanofluid, nanopaticle depoits on heater surface forms a porous layer and causes surface roughness change of heater surface. Due to this porous layer trapping of liquid near heater surface takes place which leads to delay in occurrence of CHF.

Also, these porous layer causes breaking of voids near heater surface and prevent the formation of vapor blanket on the heater surface, thus CHF enhancement occurs.

Nanoparticle deposition increases nucleation site density. Due to increase in nucleation site density bubble departure diameter decreases. Due to this, coalescence of bubble decreases and vapor blanketing on the heater surface decreases. Also, reduced bubble departure diameter causes increased bubble departure frequency as small size bubble forms. Irregularity due to roughness allows bubble to leave heater surface more easily.

Surface roughness of wire used in 15 gram/liter nanofluid, is less than that of 12 gram/liter nanofluid. Hence less $\mathrm{CHF}$ enhancement is occurred in 15 gram/liter nanofluid than 12 gram/liter nanofluid.

\section{CONCLUSION}

Critical heat flux of nanofluid is more than distilled water. $\mathrm{CHF}$ enhancement increases with nanoparticle concentration from $3 \mathrm{gram} / \mathrm{liter}$ to from $12 \mathrm{gram} / \mathrm{liter}$ while at 15 gram/liter concentration $\mathrm{CHF}$ is less than 12 gram/liter but more than distilled water.

Surface roughness measurement of heater surface used in pool boiling of nanofluid shows, Surface roughness increases from 3 gram/liter to 12 gram/liter. While for 15 gram/liter nanofluid pool boiling, extra nanoparticle might be deposited in micro cavities of porous layer and causes reduction in surface roughness as compared to 12 gram/liter nanoparticle concentration. Hence less CHF enhancement is occurred in 15 gram/liter nanofluid than 12 gram/liter nanofluid.

Nanoparticle depositions increase nucleation site density. Due to increase in nucleation site density bubble departure diameter decreases. Due to this, coalescence of bubble decreases and vapor blanketing heater surface decreases. Also, reduced bubble departure diameter causes increased bubble departure frequency as small size bubble forms. Irregularity due to roughness allows bubble to leave heater surface more easily hence ability to wet the heater surface increases which leads to delaying CHF.

Finally, it can be concluded that in pool boiling of nanofluid, nanoparticle deposition on heater surface causes increase in surface roughness of heater surface which causes $\mathrm{CHF}$ enhancement. Hence nanofluid has great potential for critical heat flux enhancement and design of safety system. This gives an opportunity for engineers to develop highly compact and effective heat transfer equipment. 


\section{FUTURE SCOPE}

Nanoparticle deposits on heater surface forming layer on heater surface. The exact thickness of nanopaticle layer on heater surface up to which $\mathrm{CHF}$ enhancement can occurs needs to be find out. Effect of nanopartcle thickness on wettability of heater surface is needs to be carried by measuring contact angle and capillary wicking. Also, effect of nanoparticle layer thickness on porosity needs to be found out.

\section{REFERENCES}

[1] Mourgues A, Hourtane V, Muller T, Charles M.C. (2013)," Boiling behaviors and critical heat flux on a horizontal and vertical plate in saturated pool boiling with and without $\mathrm{ZnO}$ nanofluid", International Journal of Heat and Mass Transfer 57, pp.595-607.

[2] Sharma V.I, Buongiorno J. McKrell T.J, Hu L.W. (2013)," Experimental investigation of transient critical heat flux of water-based zinc-oxide nanofluids", International Journal of Heat and Mass Transfer 61, pp. 425-431.

[3] Lee J.H, Lee T, Jeong Y. H (2013)," The effect of pressure on the critical heat flux in water based nanofluids containing $\mathrm{Al}_{2} \mathrm{O}_{3}$ and $\mathrm{Fe}_{3} \mathrm{O}_{4}$ nanoparticles", International Journal of Heat and Mass Transfer 61, pp.432-438.

[4] Kathiravan R., Kumar R, Gupta A, Chandra R. (2010)," Preparation and pool boiling characteristics of copper nanofluids over a flat plate heater", International Journal of Heat and Mass Transfer 53, pp. 1673-1681.

[5] Kim H, Kim J., Kim M.H (2006)," Effect of nanoparticles on CHF enhancement in pool boiling of nanofluids", International Journal of Heat and Mass Transfer 49, pp. 5070-5074.

[6] Hegde R.N, Rao S.S, Reddy R.P (2012)," Experimental studies on CHF enhancement in pool boiling with CuO-water nanofluid", Heat Mass Transfer 48, pp.1031-1041.

[7] Hegde R.N, Rao S.S, Reddy R.P (2012)," Investigations on Heat Transfer Enhancement in Pool Boiling with Water-CuO Nano-Fluids", Journal of Thermal Science Vol.21, No.2, pp. 179-183.

[8] Jung J.Y, Kim E.S, Nam Y, Kang Y.T (2013)," The study on the critical heat flux and pool boiling heat transfer coefficient of binary nanofluids $\left(\mathrm{H}_{2} \mathrm{O} / \mathrm{LiBr}+\right.$ $\mathrm{Al}_{2} \mathrm{O}_{3}$ )", International Journal of refrigeration 36, pp.1056-1061.

[9] Park S.D, Bang I.C. (2014)," Experimental study of a universal CHF enhancement mechanism in nanofluids using hydrodynamic instability", International Journal of Heat and Mass Transfer 70, pp. 844-850.

\section{BIOGRAPHIES}

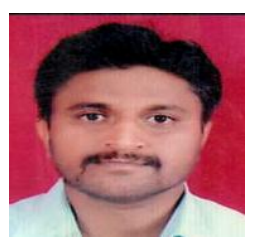

Mr. Ganesh Annasaheb Matre pursuing ME in Mechanical from MSSCET, Jalna (M.S.) India. His research interests are in heat $\&$ mass transfer, nanofluids.

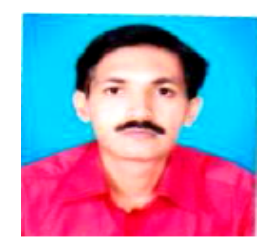

Prof. R.L. Karwande working as Associate professor in Mechanical Engineering Department, MSSCET, Jalna, (M.S.) India. His research interests are in heat \& mass transfer, nanofluids. 